\title{
Consequences of Phenytoin Exposure on Hepatic Cytochrome P450 Expression during Postnatal Liver Maturation in Mice ${ }^{\mathbb{}}$
}

\author{
Stephanie C. Piekos, Liming Chen, Pengcheng Wang, Jian Shi, Sharon Yaqoob, Hao-Jie Zhu, \\ Xiaochao Ma, and Xiao-bo Zhong
}

Department of Pharmaceutical Sciences, School of Pharmacy, University of Connecticut, Storrs, Connecticut (S.C.P., L.C., S.Y., X.-b.Z.); Department of Pharmaceutical Sciences, School of Pharmacy, University of Pittsburgh, Pittsburgh, Pennsylvania (P.W., X.M.); and Department of Clinical Pharmacy, College of Pharmacy, University of Michigan, Ann Arbor, Michigan (J.S., H.-J.Z.)

Received February 8, 2018; accepted June 1, 2018

\begin{abstract}
The induction of cytochrome P450 (P450) enzymes in response to drug treatment is a significant contributing factor to drug-drug interactions, which may reduce therapeutic efficacy and/or cause toxicity. Since most studies on P450 induction are performed in adults, enzyme induction at neonatal, infant, and adolescent ages is not well understood. Previous work defined the postnatal ontogeny of drug-metabolizing P450s in human and mouse livers; however, there are limited data on the ontogeny of the induction potential of each enzyme in response to drug treatment. Induction of P450s at the neonatal age may also cause permanent alterations in P450 expression in adults. The goal of this study was to investigate the short- and long-term effects of phenytoin treatment on mRNA and protein expressions and enzyme activities of CYP2B10, 2C29, 3A11,
\end{abstract}

and 3A16 at different ages during postnatal liver maturation in mice. Induction of mRNA immediately following phenytoin treatment appeared to depend on basal expression of the enzyme at a specific age. While neonatal mice showed the greatest fold changes in CYP2B10, 2C29, and 3A11 mRNA expression following treatment, the levels of induced protein expression and enzymatic activity were much lower than that of induced levels in adults. The expression of fetal CYP3A16 was repressed by phenytoin treatment. Neonatal treatment with phenytoin did not permanently induce enzyme expression in adulthood. Taken together, our data suggest that inducibility of drug-metabolizing P450s is much lower in neonatal mice than it is in adults and neonatal induction by phenytoin is not permanent.

\section{Introduction}

Drug-drug interactions (DDIs) are a major cause of adverse drug reactions (ADRs) and occur when one medication interferes with the efficacy or toxicity profile of another medication administered concurrently. Pharmacokinetic DDIs occur when the perpetrating drug affects the absorption, distribution, metabolism, or excretion of other victim drugs, shifting plasma concentrations outside of optimal therapeutic windows (Palleria et al., 2013). Plasma concentrations are largely determined by cytochrome P450 (P450)-mediated drug metabolism, which can be inhibited or induced by xenobiotics. Several marketed drugs induce the transcription of $\mathrm{P} 450$ genes via the activation of nuclear receptors and are implicated in clinically significant DDIs (Lin, 2006).

This study was supported by the National Institutes of Health National Institute of General Medical Sciences [Grant R01GM-118367] (to X.-b.Z.); the American Foundation for Pharmaceutical Education (to S.C.P.); the National Institutes of Health National Institute for Diabetes and Digestive and Kidney Diseases [Grant R01DK090305] (to X.M.); and the National Institutes of Health National Heart, Lung, and Blood Institute [Grant R01HL126969] (to H.-J.Z.). This study was also partly supported by the Institute for System Genomics at the University of Connecticut (to X.-b.Z.).

https://doi.org/10.1124/dmd.118.080861.

$\$$ This article has supplemental material available at dmd.aspetjournals.org.
Patients may experience attenuated therapeutic efficacy if induced $\mathrm{P} 450$ mediated metabolism decreases plasma concentration of other active drug compounds taken simultaneously. Conversely, patients could experience adverse effects due to accumulation of toxic metabolites (Zanger and Schwab, 2013).

Like adults, many infants and children are exposed to multiple medications at once, especially those that are hospitalized (Dai et al., 2016). However, DDIs in the context of pediatric patients are not as well understood as other DDIs. This is mainly due to the lack of appropriate in vitro models and the fact that clinical trials are not usually performed in pediatric patients (Björkman, 2006). Neonatal patients seem to be particularly susceptible to ADRs due to diminished clearance capacities in the first 2 years of life (Fabiano et al., 2012). It is well-established that the neonatal liver is not fully developed at birth and undergoes a period of postnatal maturation, during which metabolic function is not comparable to that of adults. Drug metabolism by P450s, in particular, varies greatly during the first 2 years after birth due to the ontogenic regulation of $\mathrm{P} 450$ gene expression (Hines, 2008). Most drugmetabolizing P450s, including CYP3A4, 2C19, and 2C29, are expressed at low levels during gestation, at birth, and during early postnatal life, and do not reach expression levels comparable to that of adults until at least 2 years of age (Treluyer et al., 1997; de Wildt et al., 1999). This causes a diminished capacity for the metabolism of many drugs and is implicated in numerous ADRs in infants (Pearce et al., 2001; Hines,

ABBREVIATIONS: ADR, adverse drug reaction; AED, antiepileptic drug; BSA, bovine serum albumin; CAR, constitutive androstane receptor; DDI, drug-drug interaction; GAPDH, glyceraldehyde-3-phosphate dehydrogenase; IDA, information-dependent acquisition; MPB, mobile phase B; MS, mass spectrometry; P450, cytochrome P450; PBS, phosphate-buffered saline; RT-PCR, real-time polymerase chain reaction; SWATH-MS, sequential window acquisition of all theoretical mass spectra; TOF, time-of-flight. 
2013). Other enzymes, such as CYP3A7, are only expressed in the fetal and early postnatal liver and become undetectable once the liver is fully matured (Lacroix et al., 1997).

Whereas the postnatal ontogeny of P450s in humans has been established, the induction of $\mathrm{P} 450$ s in response to drug treatment has not been well studied in pediatric populations at different stages of early development. It is largely unknown to what extent P450 activity can be induced in neonates and children compared with adults. Whether the capacity for enzymatic induction varies at different ages during postnatal liver maturation is also not understood. Several studies have additionally suggested neonatal exposures to inducer drugs, particularly the antiepileptic drug (AED) phenobarbital, can cause permanent alterations to expression and activities of P450s in adult rodents (Agrawal and Shapiro, 1996, 2005; Tien et al., 2015, 2017; Piekos et al., 2017). There also appears to be a window of sensitivity during neonatal life that allows the imprinting of lasting changes to $\mathrm{P} 450$ expression following treatment (Tien et al., 2015). This effect has not yet been validated with other small molecule drugs.

The goal of this work was to further examine the postnatal liver's capacity for $\mathrm{P} 450$ induction in response to inducer treatment at different ages spanning neonatal, infant, and adolescent stages in mice. This is a continuation of our previous studies that investigated the effects of neonatal phenobarbital treatment on expression of P450s in adult mice. Whereas no animal model is a perfect representation of human drug metabolism, the mouse is a useful in vivo system for studying developmental responses to drug treatment in a relatively short amount of time and for establishing proof-of-concepts prior to human pharmacokinetic studies (Turpeinen et al., 2007). Both shortand long-term effects of a single phenytoin dose on P450 expression and function were investigated, utilizing the novel sequential window acquisition of all theoretical mass spectra (SWATH-MS) method to quantify protein concentrations. Phenytoin was selected as an inducer because, like phenobarbital, it is an AED commonly used to treat neonatal seizures and a potent inducer of drug-metabolizing P450s (Wang et al., 2004; Jackson et al., 2006; Zeller and Giebe, 2015). Based on previous studies, we hypothesized the neonatal liver is particularly sensitive to P450 induction by drug treatment and early life phenytoin exposure causes permanent alterations to P450 metabolism in adulthood.

\section{Materials and Methods}

Chemicals and Reagents. Phosphate-buffered saline (PBS), 5,5-diphenylhydantoin salt (phenytoin), trifluoroacetic acid, formic acid, and acetonitrile were purchased from Sigma-Aldrich (St. Louis, MO). Urea and dithiothreitol were obtained from Fisher Scientific Co. (Pittsburgh, PA). Iodoacetamide and ammonium bicarbonate were purchased from Acros Organics (Morris Plains, $\mathrm{NJ}$ ). Tosyl phenylalanyl chloromethyl ketone-treated trypsin was obtained from Worthington Biochemical Corporation (Freehold, NJ). Standard bovine serum albumin (BSA) was purchased from Thermo Fisher Scientific (Waltham, MA).

Animals. C57B1/6 mice (Jackson Laboratories, Bar Harbor, ME) were housed in accordance with the animal care guidelines outlined by the American Association for Animal Laboratory Sciences and were bred under standard conditions in the Animal Resources Facility at the University of Connecticut. The use of these animals was approved by the University of Connecticut's Institutional Animal Care and Use Committee. At 12 weeks of age, mice were set up into breeding pairs. To study short-term effects of drug treatment at different ages during postnatal development, mice were administered a single dose of phenytoin $(100 \mathrm{mg} / \mathrm{kg}$ ) or PBS vehicle control intraperitoneally on days 5, 10, 15, 20, 30, or 60 following birth. Twenty-four hours after the treatment, mice were sacrificed and liver samples were collected. To study long-term effects of drug treatment, mice on day 5 after birth were administered either phenytoin $(100 \mathrm{mg} / \mathrm{kg})$ or PBS vehicle control intraperitoneally. Following treatment, mice were sacrificed at different ages (day 10, 15, 20, 30, or 60 after birth) and livers were collected.
Livers with gallbladders removed were snap frozen in liquid nitrogen and then stored at $-80^{\circ} \mathrm{C}$. In both the short- and long-term studies, 4-6 livers were collected at each age for both control and treatment groups. Both male and female mice were included in this study.

Total RNA Extraction, Reverse Transcription, and Real-Time Polymerase Chain Reaction. Total RNAs were isolated from whole livers using TRIzol reagent according to the manufacturer's protocol (Life Technologies, Guilford, CT). RNA concentrations were measured using a NanoDrop spectrophotometer (NanoDrop Technologies, Wilmington, DE) at a wavelength of $260 \mathrm{~nm}$. To obtain cDNA, reverse transcription was performed using an iScript Reverse Transcription Supermix according to the manufacturer's protocol (Bio-Rad, Hercules, CA). Real-time polymerase chain reaction (RT-PCR) was performed using a CFX-96 thermocycler system (Bio-Rad) with TaqMan gene expression assays for glyceraldehyde-3-phosphate dehydrogenase (GAPDH), CYP3A16, 3A11, 2B10, and 2C29 (Thermo Fisher Scientific). Fold changes of P450 expression in the phenytoin-treated group compared with the PBS control group at each postnatal age were calculated using the $2^{-\Delta \Delta \mathrm{Ct}}$ method described by Livak and Schmittgen (2001) with a normalization of P450 expression to GAPDH. A consistent expression level of GAPDH is observed by either RNA-Seq or RT-PCR in mouse liver during postnatal maturation (Supplemental Fig. 1).

Protein Sample Preparation and Liquid Chromatography-Tandem Mass Spectrometry-Based Quantification. Whole mouse livers were chopped into small pieces using scissors and homogenized in PBS ( $\mathrm{pH}$ 7.4) by a tissue grinder equipped with a Teflon pestle on ice. Liver S9 fractions were obtained by centrifuging the homogenate at $4^{\circ} \mathrm{C}$ at $10,000 \mathrm{~g}$ for 30 minutes. The supernatant containing the $\mathrm{S} 9$ fractions was transferred to a Beckman ultracentrifuge tube and centrifuged at $300,000 \mathrm{~g}$ for 20 minutes. The liver microsomes were obtained by resuspending the pellet with PBS using the tissue grinder. Protein concentration was determined using a Pierce BCA Protein Assay Kit (Thermo Fisher Scientific). Protein digestion was conducted according to a previously reported LysC/Trypsin combinatorial digestion protocol (Glatter et al., 2012) with minor modifications. An aliquot of $80 \mu \mathrm{g}$ liver microsomal protein was mixed with the internal standard BSA $(0.2 \mu \mathrm{g})$. After adding a 10 -fold volume of precooled acetone, the mixture was incubated at $-20^{\circ} \mathrm{C}$ for 2 hours and centrifuged. The supernatants were removed and the precipitated proteins were washed with $80 \%$ ethanol and then air-dried at room temperature. Proteins were resuspended in $4 \mathrm{mM}$ DDT in $8 \mathrm{M}$ urea solution containing $100 \mathrm{mM}$ ammonium bicarbonate. Samples were sonicated and then incubated at $37^{\circ} \mathrm{C}$ for 45 minutes. After samples were cooled down to room temperature, $20 \mathrm{mM}$ iodoacetamide in $8 \mathrm{M}$ urea/100 mM ammonium bicarbonate was added and incubated for 30 minutes at room temperature for alkylation. Following incubation, the urea concentration was adjusted to $6 \mathrm{M}$ by adding $61.6 \mu 1$ of $50 \mathrm{mM}$ ammonium bicarbonate. Lysyl endopeptidase (Wako Chemicals, Richmond, VA) was added at an enzyme-toprotein ratio of $1: 100$ for the first step protein digestion for 6 hours at $37^{\circ} \mathrm{C}$. Samples were diluted to $1.6 \mathrm{M}$ urea followed by a second digestion with trypsin at an enzyme-to-protein ratio of 1:50 for an overnight incubation at $37^{\circ} \mathrm{C}$. Digestion was terminated by adding $1 \mu \mathrm{l}$ trifluoroacetic acid.

Digested peptides were extracted and purified using Waters Oasis HLB columns (Waters Corporation, Milford, MA) according to the manufacturer's instructions. Eluted peptides were dried in a Speed Vac SPD1010 (Thermo Scientific, Hudson, $\mathrm{NH}$ ) and reconstituted in $3 \%$ acetonitrile with $0.1 \%$ formic acid. The peptide samples were centrifuged and one-half of the supernatant was collected and supplemented with synthetic iRT standard solutions (Biognosys AG, Cambridge, MA) prior to liquid chromatography-tandem mass spectrometry (MS) analysis.

Peptides were analyzed in a TripleTOF 5600+ mass spectrometer (AB Sciex, Framingham, MA) coupled with an Eksigent 2D Plus LC System (Eksigent Technologies, Dublin, CA). Liquid chromatography separation was performed via a trap-elute configuration, which included a trapping column (ChromXP C18-CL, $120 \AA ̊ 丿, 5 \mu \mathrm{m}, 0.3 \mathrm{~mm}$ cartridge; Eksigent Technologies) and an analytical column (ChromXP C18-CL, $120 \AA$, $150 \times 0.3 \mathrm{~mm}, 5 \mu \mathrm{m}$; Eksigent Technologies). The mobile phase consisted of water with $0.1 \%$ formic acid (phase A) and acetonitrile with $0.1 \%$ formic acid (phase B) (Avantor, Center Valley, PA). A total of $6 \mu \mathrm{g}$ protein was injected for analysis. Peptides were trapped and cleaned on the trapping column, with phase A delivered at a flow rate of $10 \mu \mathrm{l} / \mathrm{min}$ for 3 minutes, followed by separation on the analytical column with a gradient elution at a flow rate of $5 \mu \mathrm{l} / \mathrm{min}$. For column equilibration, the gradient time program was set as follows for phase B: 0-68 minutes at 3\%-30\%; 68-73 minutes at 

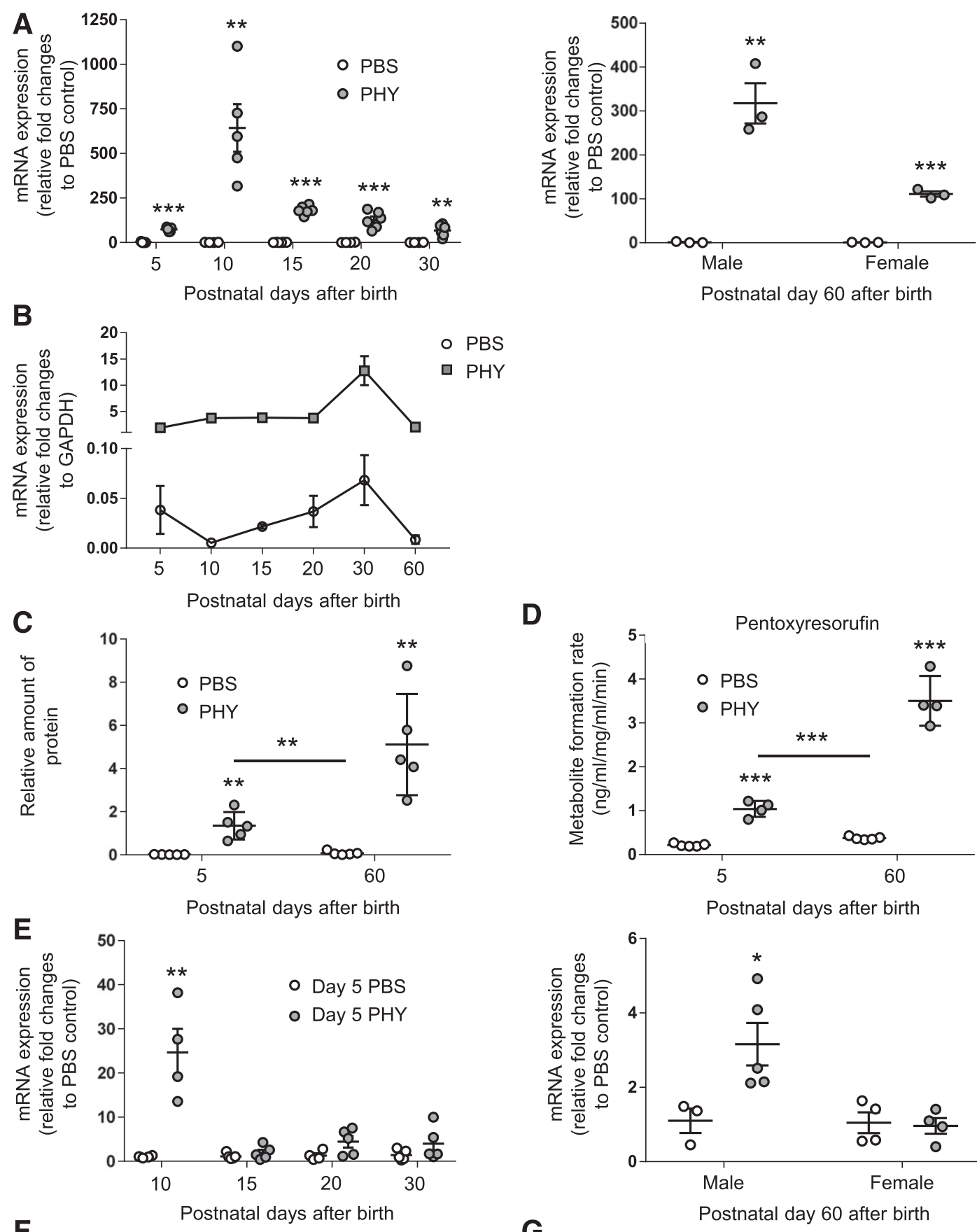

Postnatal days after birth
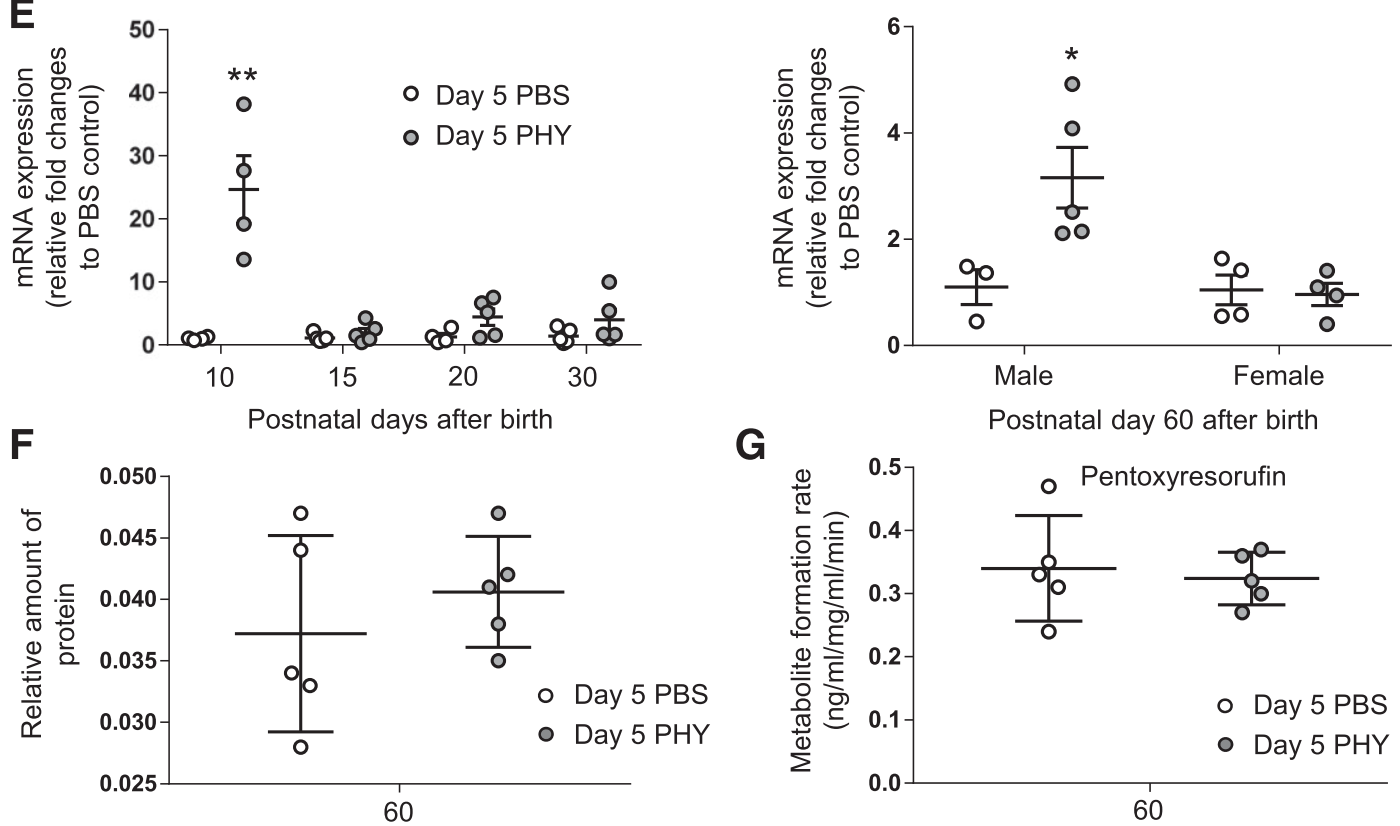

Postnatal days after birth

G

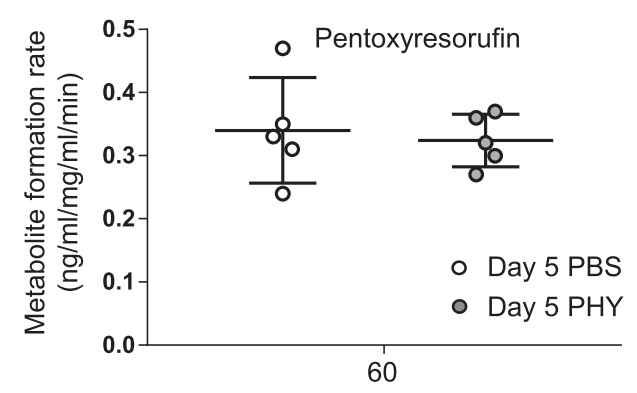

Postnatal days after birth

Fig. 1. Effects of phenytoin (PHY) treatment on the expression and activity of CYP2B10 at different ages during postnatal maturation. Male and female mice were treated with either vehicle control (PBS) or $100 \mathrm{mg} / \mathrm{kg}$ PHY at different ages following birth. The short-term effects of PHY treatment were measured 24 hours after treatment. Changes in gene expression were evaluated at the mRNA level using RT-PCR, and then fold changes were calculated using the $2^{-\Delta \Delta C t}$ method. Data points represent fold changes in gene expression of individual mice treated with PBS or PHY compared with the average $\triangle \mathrm{Ct}$ of mice that received PBS control (A). Ct values from RT-PCR experiments were also compared with the GAPDH Ct value in each individual mouse and the differences are expressed as $\left.2^{-[\mathrm{Ct}(\mathrm{P} 450)}-\mathrm{Ct}(\mathrm{GAPDH})\right](\mathrm{B})$. The dotted line 
$30 \%-40 \% ; 73-75$ minutes at $40 \%-80 \% ; 75-78$ minutes at $80 \% ; 78-79$ minutes at $80 \%-3 \%$; and finally $79-90$ minutes at $3 \%$. The TripleTOF instrument was operated in positive ion mode with ion spray voltage floating at $5500 \mathrm{v}$, ion source gas one at $28 \mathrm{psi}$, ion source gas two at $16 \mathrm{psi}$, curtain gas at $25 \mathrm{psi}$, and source temperature at $280^{\circ} \mathrm{C}$.

To generate the reference spectral library for SWATH-MS data analysis, information-dependent acquisition (IDA) was performed for three pooled mouse liver microsome samples with equal protein amounts. The IDA method included a 250 millisecond time-of-flight (TOF)-MS scan from 400 to $1250 \mathrm{Da}$, followed by a tandem MS scan in high-sensitivity mode from 100 to $1500 \mathrm{Da}(50$ millisecond accumulation time, $10 \mathrm{ppm}$ mass tolerance, charge state from +2 to +5 , rolling collision energy and dynamic accumulation) of the top 30 precursor ions from the TOF-MS scan. The IDA data from the pooled mice liver microsomes were searched by MaxQuant (version 1.5.3.30; Max Planck Institute of Biochemistry, Planegg, Germany). The mouse FASTA file with 16,911 protein entries was downloaded from Uniport on August 29, 2016, and used as the reference sequences for searches with trypsin/P as the protease. Peptide length was set between 7 and 25 residues with up to two missed cleavage sites allowed. Carbamidomethyl was set as a fixed modification. A false discovery rate of 0.01 was used as the cutoff for both peptide and protein identification.

All microsomes samples were analyzed using a SWATH-MS method with the "SWATH (VW 100)" isolation scheme, which is comprised of a 250 millisecond TOF-MS scan from 400 to $1250 \mathrm{Da}$, followed by MS/MS scans from 100 to $1500 \mathrm{Da}$ performed on all precursors in a cyclic manner. The accumulation time was 50 milliseconds per isolation window, resulting in a total cycle time of 2.8 seconds. The spectral alignment and target data extraction of the SWATH-MS data were performed on Skyline-daily (version 3.7.1.11271; University of Washington, Seattle, WA) with the reference spectral library generated from the aforementioned IDA searches. The MS1 and MS/MS filtering were both set as TOF mass analyzer with the resolution power of 30,000 and 15,000, respectively. The retention time prediction was based on the auto-calculate regression implemented in the iRT calculator. Proper peak selection was reviewed manually with the automated assistance of Skyline-daily. The surrogate peptides used for the quantification of CYP2B10, 2C29, 3A11, and 3A16 proteins are listed in Supplemental Table 1. The selections were based on the uniqueness and chromatographic performance of these peptides. The peak areas of the top 3-5 fragment ions were summed up and normalized to the internal standard BSA. The BSA-normalized peak area of each peptide was further divided by the average peak area of the 30 samples to calculate the relative abundance of the peptide. The average of relative abundance of all surrogate peptides of a protein was used to determine protein relative abundance.

Evaluation of Enzymatic Activities. Liver tissues were homogenized in icecold $100 \mathrm{mM}$ PBS (pH 7.4) and S9 fractions were obtained by centrifugation. Protein concentrations were determined using a Pierce BCA Protein Assay Kit (Thermo Fisher Scientific, Rockford, IL). Pentoxyresorufin $O$-dealkylation, paclitaxel 6-hydroxylation, and midazolam 1'-hydroxylation, were used as probes for CYP2B10 (Lam et al., 2010), CYP2C29 (Gustafson et al., 2005), and CYP3A11 (Lam et al., 2010) activities, respectively. Incubations were carried out in $100 \mathrm{mM}$ PBS (pH 7.4), containing $0.1 \mathrm{mg}$ of mouse liver S9 protein and $30 \mu \mathrm{M}$ substrate for a final volume of $95 \mu \mathrm{l}$. The reactions were initiated by adding $5 \mu \mathrm{l}$ of $20 \mathrm{mM}$ NADPH and continued for 30 minutes for pentoxyresorufin and paclitaxel or 10 minutes for midazolam. Incubations were terminated by adding $100 \mu \mathrm{l}$ of ice-cold acetonitrile.

After centrifugation at $15,000 \mathrm{rpm}$, a $1.0 \mu \mathrm{l}$ aliquot was injected into a Waters Synapt G2-S QTOFMS system for metabolite quantification analysis. Chromatographic separation of metabolites was performed on an Acquity UPLC BEH C18 column $(2.1 \times 50 \mathrm{~mm}, 1.7 \mu \mathrm{m}$; Waters Corporation). Mobile phase A consisted of $0.1 \%$ formic acid in water and mobile phase B (MPB) consisted of $0.1 \%$ formic acid in acetonitrile. The gradient for aqueous extraction began at 5\% MPB and held for 0.5 minutes, followed by 5 minute linear gradient to $95 \% \mathrm{MPB}$, held for 2 minutes, and decreased to $5 \%$ MPB for column equilibration. The flow rate of the mobile phase was $0.50 \mathrm{ml} / \mathrm{min}$ and the column temperature was maintained at $50^{\circ} \mathrm{C}$. The
G2-S QTOFMS system was operated in resolution mode (resolution 20,000) with electrospray ionization. The source and desolvation temperatures were set at 150 and $500^{\circ} \mathrm{C}$, respectively. Nitrogen was applied as the cone gas $(50 \mathrm{l} / \mathrm{h})$ and desolvation gas $(800 \mathrm{l} / \mathrm{h})$. The capillary and cone voltages were set at $0.8 \mathrm{kV}$ and $40 \mathrm{~V}$. The data were acquired in positive ionization mode. QTOFMS was calibrated with sodium formate and monitored by the intermittent injection of lock mass leucine encephalin $(\mathrm{m} / \mathrm{z}=556.2771)$ in real time. Quanlynx software (Waters Corporation) was used for quantification of the concentration of metabolites.

Enzyme reactions were validated to be linear over the 30-minute incubation periods. The linear ranges of detection for resorufin, 1 'hydroxymidazolam, and hydroxytaxol were 1-300 ng/ml, 0.2-200 mg/ml, and 8-1000 ng/ml, respectively.

Statistical Analysis. Data are presented as the mean \pm S.E. Statistical analyses were performed using the GraphPad Prism 7 software program (GraphPad Software, Inc., La Jolla, CA). Comparisons between groups were done using Student's $t$ test and were determined using the two-stage linear step-up procedure of Benjamini, Krieger, and Yekutieli (2006) with $\mathrm{Q}=1 \%$. A value of $P<0.05$ was considered to be significant.

\section{Results}

To evaluate the impact of phenytoin exposure on the expression and function of drug-metabolizing $\mathrm{P} 450$ s throughout postnatal maturation, a mouse model was used. Short-term effects of drug treatment were evaluated at 24 hours following administration of a single dose of phenytoin in mice at different ages. Long-term effects of drug treatment were evaluated by administering a single dose of phenytoin at the age of 5 days after birth and then collecting livers at different time points throughout development, beginning on day 10 after birth. When comparing mouse to human ages (and considering total lifespans), 9 days in the mouse has been compared with 1 year in the human. Additionally, mice are weaned between days 21 and 28 of age, while humans are weaned between 6 and 12 months of age (Dutta and Sengupta, 2016). Based on this, the age on day 5 in mouse would correlate with roughly the first 3-6 months of life in humans when hepatic P450 expression is known to be rapidly changing. The expression of hepatic murine CYP2B10, 2C29, 3A11, and 3A16 enzymes was evaluated as representative members of the CYP2B, 2C, and $3 \mathrm{~A}$ subfamilies that are known to be involved in the metabolism of xenobiotics and drugs across species (Martignoni et al., 2006). The effect of drug treatment on each enzyme was measured at the mRNA level using RT-PCR, at the protein level using SWATH-MS quantification, and at the enzymatic activity level using in vitro P450 probe substrates and liquid chromatography MS quantification. SWATH-MS is a relatively novel method for measuring protein concentrations, but previous studies have suggested lower limits of peptide quantitation in the 0.1-10 fmol range (Collins et al., 2017). Both male and female mice were evaluated collectively for data presented at ages younger than day 30; however, male and female data were evaluated separately on day 60 after birth. At each time point, mice that received drug treatment were compared against age-matched mice that received a vehicle control.

Effects of Phenytoin Exposure on CYP2B10 Expression, Induction, and Function throughout Postnatal Maturation. The fold increase of CYP2B10 mRNA induction 24 hours following phenytoin administration was the greatest of all P450s measured; however, the large value for fold induction may be overstated due to low basal expression of CYP2B10 in the liver compared with other enzymes

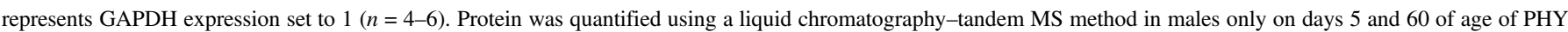

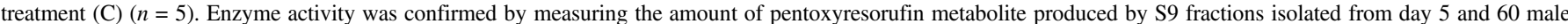

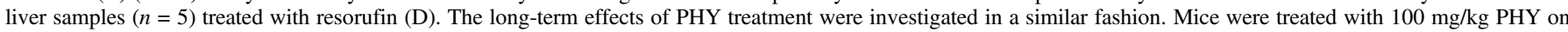

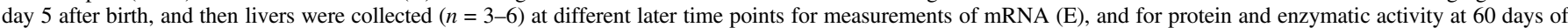
age $(\mathrm{F}$ and $\mathrm{G})$. The data are presented as mean \pm S.E. $* P<0.05 ; * * P<0.01 ; * * * P<0.001$. 

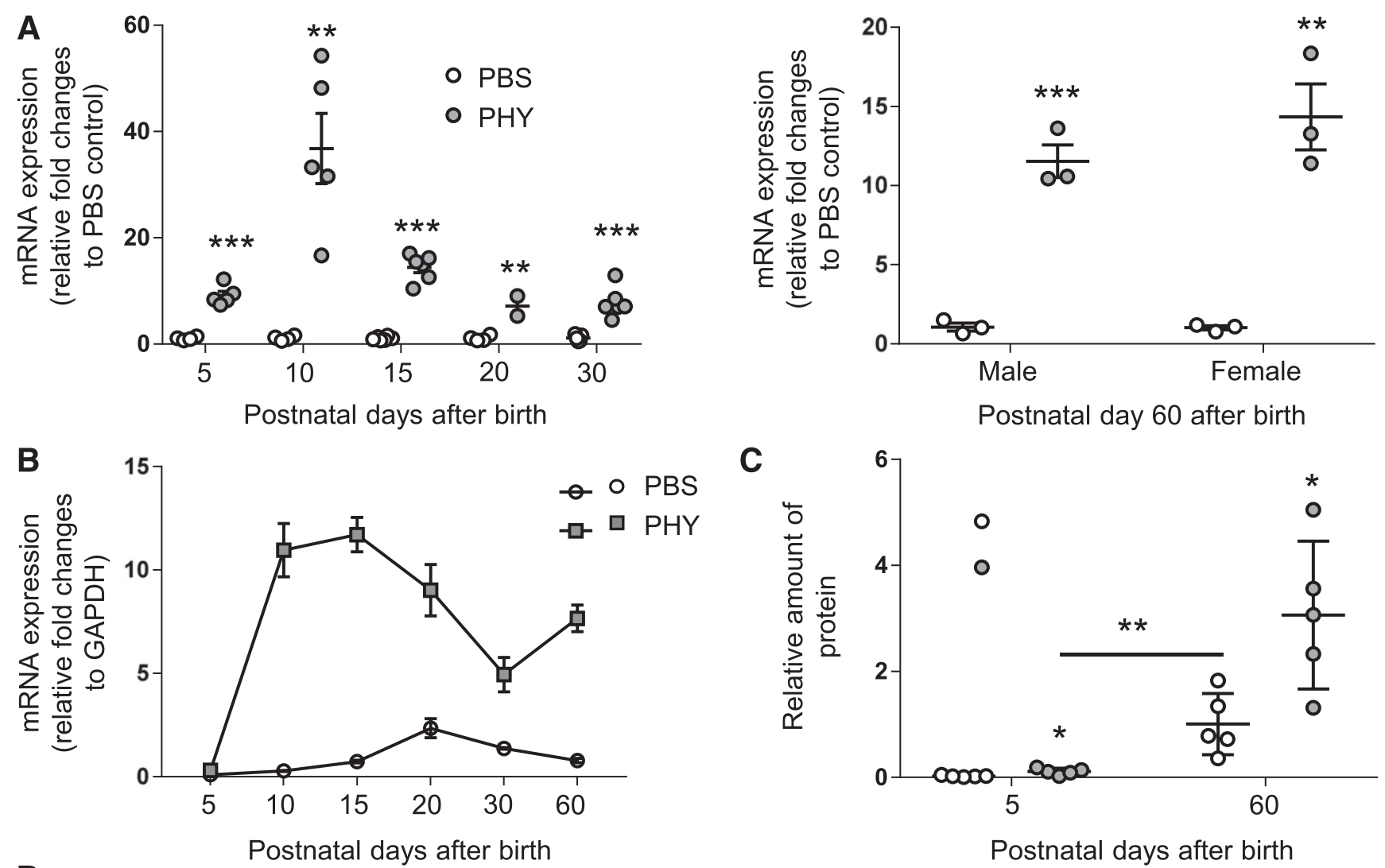

C
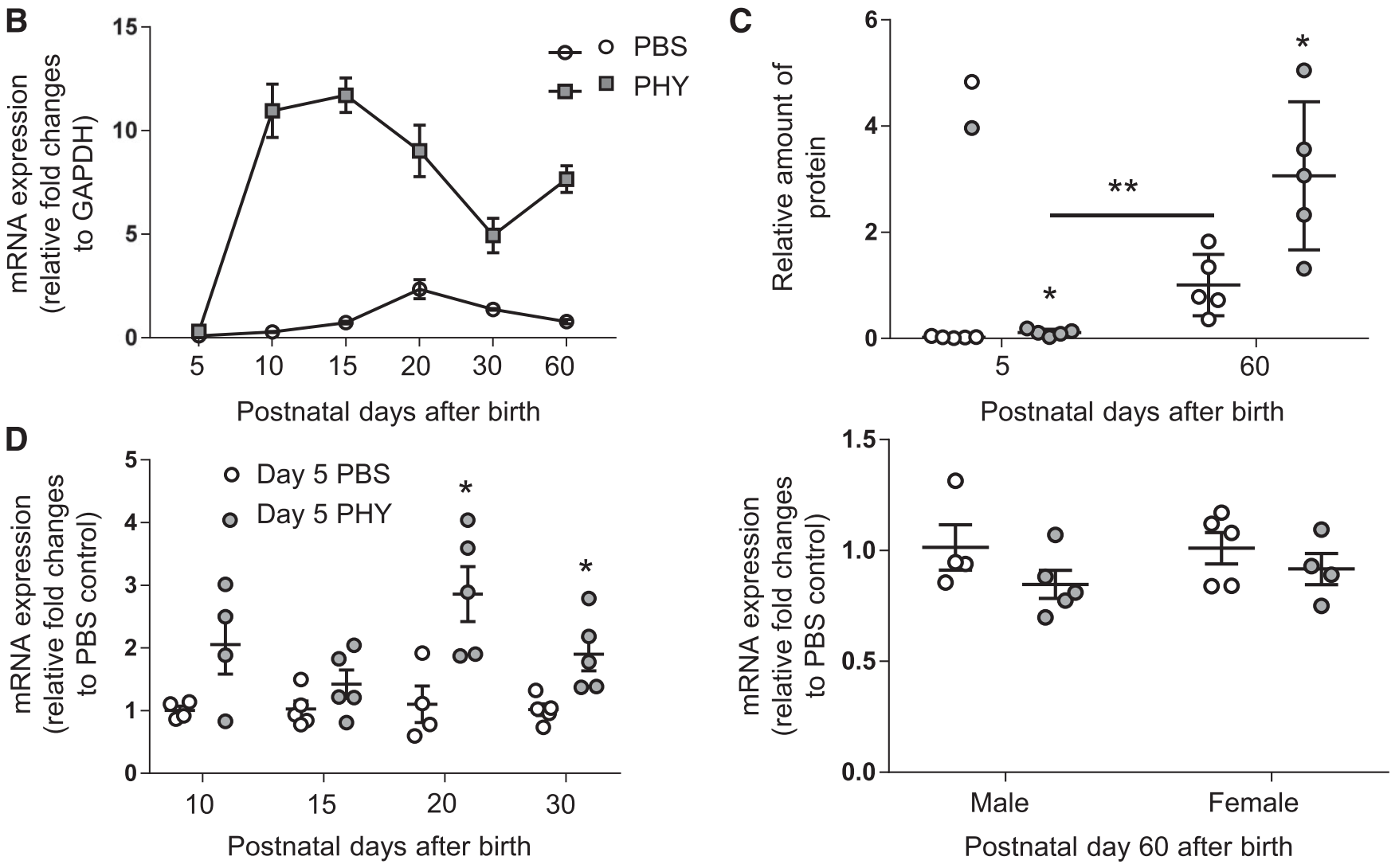

Postnatal day 60 after birth

E

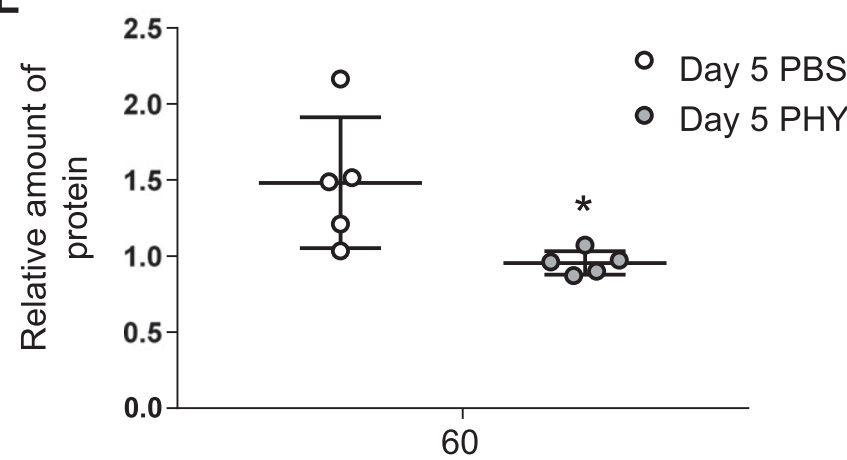

Postnatal days after birth

Fig. 2. Effects of phenytoin (PHY) treatment on the expression of CYP2C 29 at different ages during postnatal maturation. Male and female mice were treated with either vehicle control (PBS) or $100 \mathrm{mg} / \mathrm{kg}$ PHY at different ages following birth. The short-term effects of PHY treatment were measured 24 hours after treatment. Changes in gene expression were evaluated at the mRNA level using RT-PCR, and then fold changes were calculated using the $2^{-\Delta \Delta \mathrm{Ct}}$ method. Data points represent fold changes in gene expression of individual mice treated with PBS or PHY compared with the average $\triangle \mathrm{Ct}$ of mice that received PBS control (A). Ct values from RT-PCR experiments were also compared with the GAPDH Ct value in each individual mouse and the differences are expressed as $2^{-[\mathrm{Ct}(\mathrm{P} 450)-\mathrm{Ct}(\mathrm{GAPDH})]}(\mathrm{B})$. The dotted line represents GAPDH 
(Fig. 1A). Mice at 10 days of age showed the greatest fold change in mRNA expression when compared with control, whereas fold changes at other ages were more comparable to those observed in adult mice following phenytoin treatment. Adult males also had higher fold changes than females at day 60; however, adult male mice are known to have lower basal CYP2B10 expression than females. When comparing gene expression to GAPDH, which was unaffected by phenytoin treatment, CYP2B10 mRNA was much less abundant than GAPDH in control mice but reached similar levels following drug exposure (Fig. 1B). The surge in CYP2B10 expression at 30 days of age was also apparent and was associated with a spike in the inducibility of the enzyme.

CYP2B10 protein was also quantified 24 hours after treatment in neonatal mice at 5 days of age and adult male mice at 60 days of age (Fig. 1C). Following vehicle treatment, CYP2B10 protein was nearly undetectable in both neonates and adults; however, significant induction of protein was evident at both ages following phenytoin treatment. The inductive potential was far greater in adults than in neonates; however, induced levels of CYP2B10 in the neonate significantly exceeded basal levels in the adult. This observation was also reflected in a CYP2B10 enzyme activity assay determined by pentoxyresorufin $O$-dealkylation in S9 fractions prepared from neonatal and adult liver samples (Fig. 1D), indicating functional consequences of induction by phenytoin.

The long-term effects of phenytoin treatment on CYP2B10 were examined using the same techniques. Mice at 5 days of age were all administered a single dose of phenytoin or vehicle control and were allowed to age to designated time points. Livers were then collected and the effects on CYP2B10 mRNA and protein expression were evaluated. Five days following phenytoin treatment, CYP2B10 mRNA was still significantly induced at 10 days of age compared with mice that received vehicle (Fig. 1E). No other significant alterations were observed in CYP2B10 mRNA expression until the mice reached 60 days of age. However, the increased expression was only observed in males and to a smaller extent than the fold change observed at day 10. Howver, this long-term effect was not reflected at the protein (Fig. 1F) or enzymatic activity (Fig. 1G) levels since there were no significant differences in CYP2B10 protein or pentoxyresorufin $O$-dealkylation in adult male mice that received phenytoin treatment at 5 days of age.

Effects of Phenytoin Exposure on CYP2C29 Expression and Induction throughout Postnatal Maturation. Induction of CYP2C29 mRNA and protein expression 24 hours following phenytoin treatment was also examined at different ages. The amount of mRNA was significantly greater in mice that received phenytoin compared with mice that received vehicle at all ages tested, with 10 days of age appearing to again be the most sensitive to enzyme induction (Fig. 2A). When evaluating CYP2C29 mRNA expression relative to GAPDH expression, CYP2C29 mRNA was much less abundant in neonates at 5 days of age in PBS-treated control mice, but steadily increased to levels comparable to GAPDH at day 20 (Fig. 2B). Induced levels of CYP2C29 mRNA exceeded GAPDH expression by around 10-fold at all ages except day 5 , where it remained minimally expressed. This was also reflected in CYP2C29 protein quantified at 5 days of age following a 24-hour exposure duration to phenytoin (Fig. 2C). Phenytoin-mediated protein induction at 5 days of age was significant, but minimal compared with induction at the adult age on day 60. Induced levels of CYP2C29 protein in the neonate were significantly lower than even basal levels of the protein in the adult. Enzymatic activity of CYP2C29 could not be evaluated in these experiments due to insufficient protein isolated from prepared microsomes.

Long-term effects of neonatal phenytoin exposure on CYP2C29 expression at later ages were not apparent. Following day 5 administration of phenytoin, there were no persisting alterations to CYP2C29 mRNA (Fig. 2D) in adulthood when compared with control mice. There appeared to be significant upregulation of CYP2C29 mRNA in treated mice at 20 and 30 days of age; however, the fold change in gene expression may not be sufficient enough to produce biologic consequences. Interestingly, CYP2C29 protein expression was lower in adult mice that received phenytoin as neonates (Fig. 2E); however, we could not further determine whether this would translate into a functional decrease in CYP2C29 metabolic activity.

Effects of Phenytoin Exposure on CYP3A11 Expression, Induction, and Function throughout Postnatal Maturation. The shortterm effects on CYP3A11 mRNA induction following phenytoin treatment were evident across all ages studied during postnatal development. The greatest fold change between phenytoin-treated mice and control mice occurred in neonates at 5 days of age, presumably because this is when the basal expression of CYP3A11 is the lowest (Fig. 3A). As mice matured following birth, basal expression of CYP3A11 mRNA increased along with increased induced levels of mRNA with age (Fig. 3B). Maximal induction occurred at the adult ages (days 30 and 60), which was also reflected in the expression of CYP3A11 protein (Fig. $3 C)$. Protein quantification revealed that induced levels of CYP3A11 in the neonate at 5 days of age were not statistically different from basal levels of CYP3A11 protein in the adult. This was also confirmed by enzymatic activity analyses with midazolam in liver S9 fractions (Fig. 3D). At 5 days of age, mice treated with phenytoin had similar rates of 1-hydroxymidazolam metabolite formation as adult mice treated with vehicle control, while adult mice treated with phenytoin produced the most metabolite overall.

There also appeared to be no significant long-term effects on CYP3A11 expression or function following neonatal phenytoin exposure. Following administration at day 5 , phenytoin seemed to increase the range of CYP3A11 mRNA expression at later ages between mice, such as at 10 days of age where the S.E. in the fold changes of treated mice was larger than in control mice. However, there were no significant differences in the mean expression from control mice, except for a slight increase at 30 days of age (Fig. 3E). This was also confirmed in protein (Fig. 3F) and enzymatic activity (Fig. 3G) quantification. At the adult ages, there were no significant differences in mice that received phenytoin at 5 days of age of CYP3A11 protein expression or midazolam metabolism.

Effect of Phenytoin Exposure on the Postnatal Repression of the Fetal Enzyme CYP3A16. CYP3A16 is considered to be the fetal enzyme of the CYP3A subfamily of enzymes. While it is highly expressed immediately after birth, its expression declines steadily throughout postnatal maturation and is undetectable in the adult liver. Phenytoin treatment also appeared to significantly affect short-term CYP3A16 expression at different ages during postnatal development. Twenty-four hours after phenytoin administration, CYP3A16 mRNA was significantly suppressed in mice at all ages examined (Fig. 4A). The fold change in the decrease of expression was greatest at 20 days of age

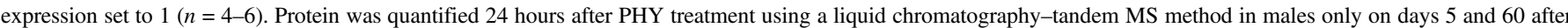

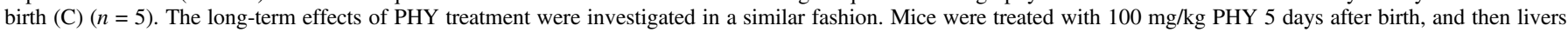

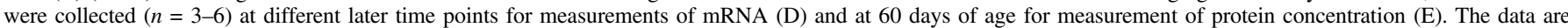
presented as mean \pm S.E. $* P<0.05$; $* * P<0.01$; *** $P<0.001$. 

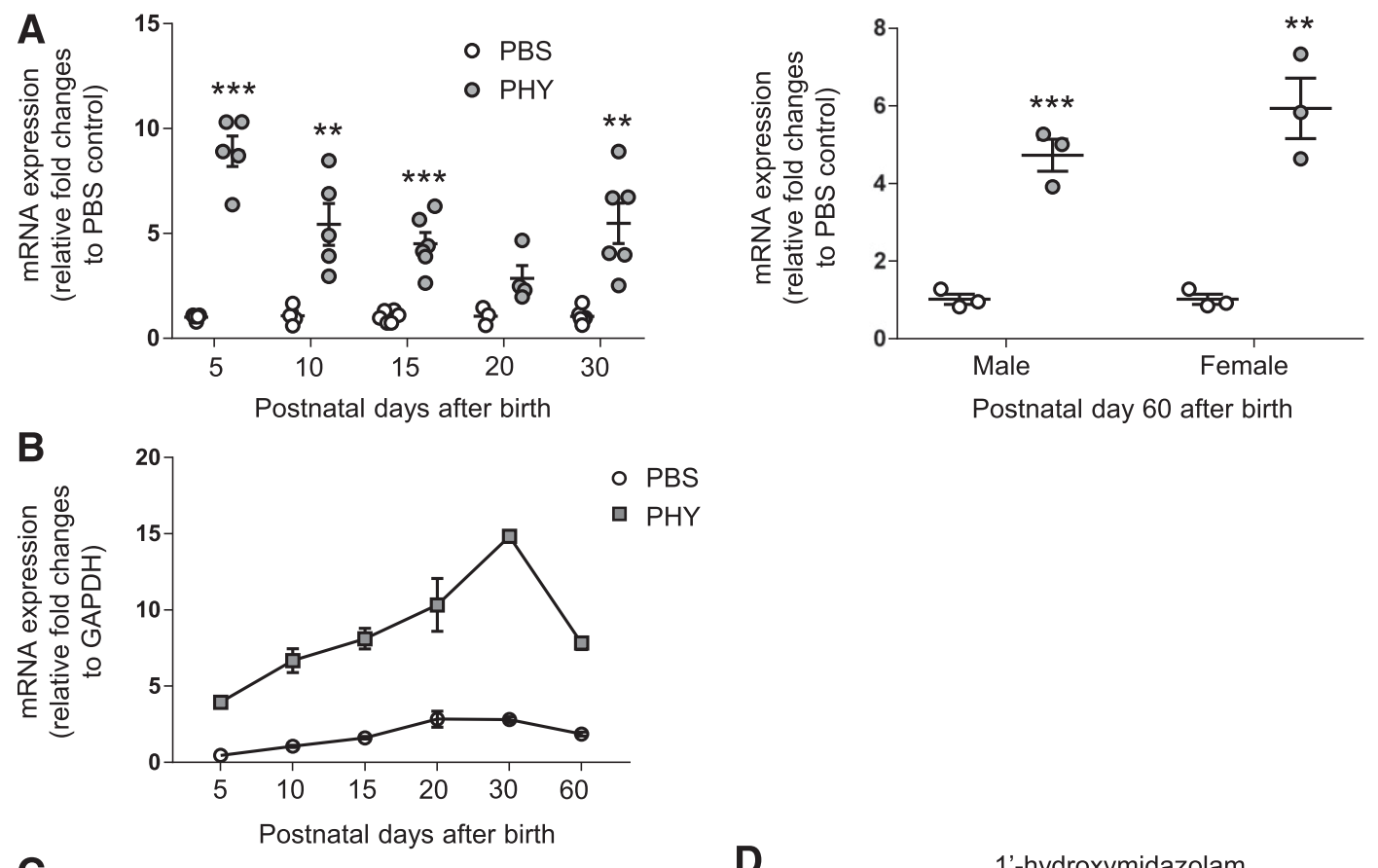

- PBS

$\square \mathrm{PHY}$
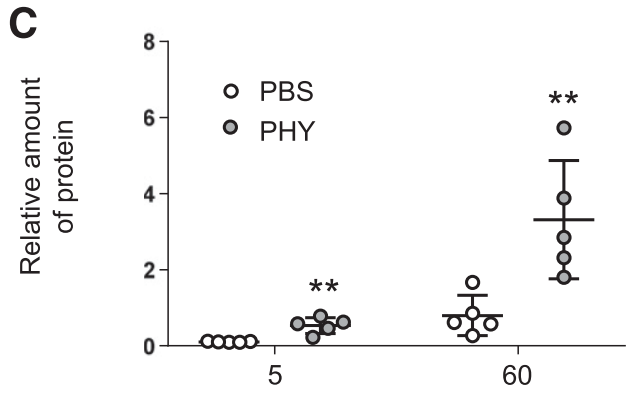

D
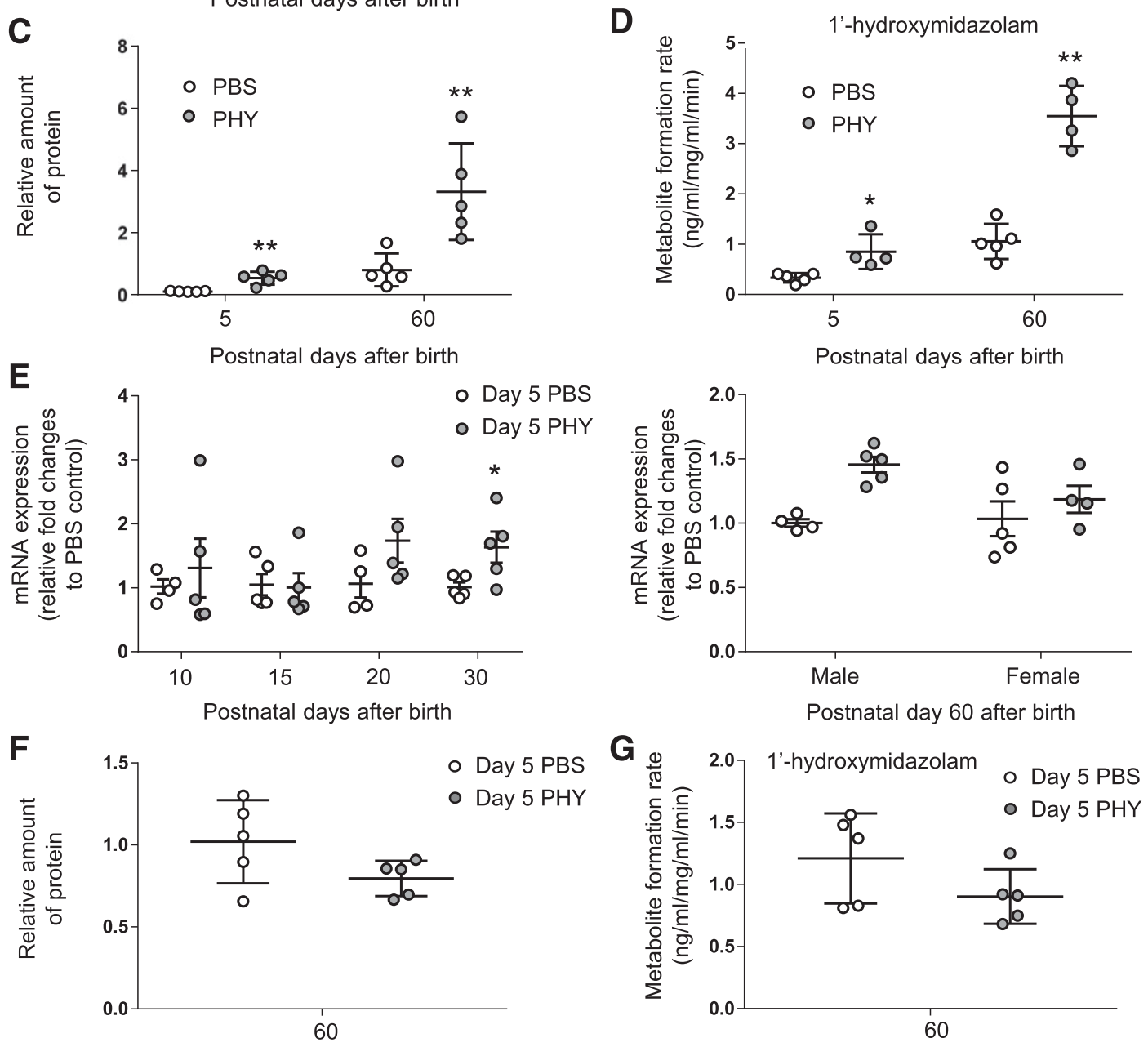

Postnatal days after birth

Postnatal days after birth

Fig. 3. Effects of phenytoin (PHY) treatment on the expression and activity of CYP3A11 at different ages during postnatal maturation. Male and female mice were treated with either vehicle control (PBS) or $100 \mathrm{mg} / \mathrm{kg}$ PHY at different ages following birth. The short-term effects of PHY treatment were measured 24 hours after treatment. Changes in gene expression were evaluated at the mRNA level using RT-PCR, and then fold changes were calculated using the $2^{-\Delta \Delta C t}$ method. Data points represent fold changes in gene expression of individual mice treated with PBS or PHY compared with the average $\Delta$ Ct of mice that received PBS control (A). Ct values from RT-PCR experiments were also compared with the GAPDH $\mathrm{Ct}$ value in each individual mouse and the differences are expressed as $2^{-[\mathrm{Ct}(\mathrm{P} 450)-\mathrm{Ct}(\mathrm{GAPDH})]}(\mathrm{B})$. The dotted line 
and this corresponded to the age in which CYP3A16 mRNA became undetectable in phenytoin-treated mice (Fig. 4B). CYP3A16 mRNA was not detected by RT-PCR in mice at 30 or 60 days of age; therefore, the data are not shown. The decrease in CYP3A16 in response to phenytoin treatment was also confirmed by protein quantification (Fig. 4C). At 5 days of age, CYP3A16 protein was decreased following drug exposure; however, not significantly. CYP3A16 protein was not detected in adults regardless of phenytoin administration.

\section{Discussion}

The present study reveals both the immediate and persistent effects on the expression and functions of several drug-metabolizing P450 enzymes following exposure to the AED drug phenytoin during murine postnatal development. Short-term induction of CYP2B10, 2C29, and 3A11 after phenytoin administration for 24 hours seems to vary in extent based on age and sex. Younger pups, such as those at 5 and day 10 days of age, had higher fold changes relative to control for P450 induction; however, these values may be overstated due to the low basal expression of P450s in the neonatal period. With increasing age, the values for fold induction decreased compared with control animals. Based on this, it is unclear how induced levels of each enzyme change independent of their basal expression levels. For this reason, we also chose to evaluate mRNA expression of each $\mathrm{P} 450$ relative to GAPDH. GAPDH expression was not altered by drug treatment and remained relatively consistent throughout postnatal development. Analyzing gene expression in relation to GAPDH allowed the ontogeny of each P450 enzyme to be observed in basal and induced states at each age. Induction of each enzyme (CYP2B10, 2C29, and 3A11) appeared to be qualitatively proportional to the basal expression level of the enzyme; the higher the mRNA expression of a $\mathrm{P} 450$ at a certain age, the greater its induction capacity. On the other hand, CYP3A16 appeared to be repressed to greater extents at increasing ages, which correlated with decreasing basal expression.

For both CYP2B10 and 2C29, day 10 appeared to be the age most sensitive to the inductive effects of phenytoin as evidenced by the greatest fold changes in mRNA expression compared with control mice. Interestingly, this correlates with our previous data that show a surge of CYP2B10 and 2C29 expression beginning at the same age (Peng et al., 2012). Both of these enzymes are primarily under the transcriptional control of the nuclear constitutive androstane receptor (CAR), while CYP3A11 is known to be regulated primarily by the nuclear pregnane $\mathrm{X}$ receptor. The expression of pregnane $\mathrm{X}$ receptor and CAR actually appear to be the highest during early postnatal life in both mouse and infant humans (Vyhlidal et al., 2006; Gunewardena et al., 2015). The consequences of elevated expression of these nuclear receptors at the neonatal stage in the expression and regulation of P450s are not understood.

The inducibility of other hepatic drug-processing genes utilizing direct activation of pregnane $\mathrm{X}$ receptor and CAR has also shown to be age dependent in mice (Li et al., 2016b). Greater fold changes in RNA expression following xenobiotic treatment are typically observed at the neonatal age. However, our study shows that despite the apparent greater extent of RNA induction at younger ages, protein expression and enzymatic activity following phenytoin treatment is still greater in adults than neonates. The expression of CYP2B10, 2C29, and 3A11 proteins is several magnitudes higher in adults than in neonates following phenytoin treatment, suggesting the adult liver has a greater capacity for enzyme induction following drug treatment than the infant liver. In the case of CYP2B10, protein expression in the neonate following phenytoin exposure exceeds that of adults in basal conditions with vehicle treatment. However, the expression of CYP2C29 protein following phenytoin treatment in the neonate does not reach adult expression levels. These data suggest that induction in response to drug treatment is not equivalent in neonatal and adult mice, even following the same dose, and adult data cannot be extrapolated to younger ages. Only liver samples from day 5 were used for protein and enzymatic activity analyses of early life, thus additional ages will need to be examined in the future.

Previous work from our laboratory has defined the ontogenic profiles of all P450s in the mouse liver from 2 days before birth through day 60 after birth (Hart et al., 2009; Peng et al., 2012). The expression patterns of the murine enzymes investigated in this study, namely, CYP2B10, 2C29, 3A11, and 3A16, follow specific ontogenic patterns throughout postnatal maturation, and our data show that induction varies depending on developmental age as well. A better understanding of the mechanisms regulating enzyme induction between the developing and fully mature mouse liver are needed to understand this observation. The expression of P450s in the human fetal, neonatal, and infant liver also follow distinct ontogenic patterns that may be specific to each enzyme. However, there are still marked differences between human and mouse P450-mediated metabolism, especially in terms of enzyme induction and regulation. Other studies have also highlighted the need for pediatric pharmacokinetics to be evaluated in age- and maturation-dependent models, rather than grouping all neonatal and infant guidelines into one pediatric category (Suzuki et al., 1994; Abduljalil et al., 2014).

The long-term effects of neonatal phenytoin exposure were also investigated in our study. Following day 5 administration, CYP2B10 was the only P450 that remained overexpressed at day 10. This mechanism will have to be further elucidated since the half-life of phenytoin in adult mice is only 16 hours (Markowitz et al., 2010); however, this might not be true for neonates. At day 60, there appears to be slight, but significant, overexpression of CYP3A11 and CYP2B10 RNA in male mice only. However, the induction was not observed in the protein or enzymatic activity analyses. Interestingly, CYP2C29 protein expression is significantly downregulated at day 60 following neonatal phenytoin exposure, despite no significant changes observed at the mRNA level.

Additional studies will be necessary to further distinguish why neonatal exposure to phenobarbital produces overexpression of $\mathrm{P} 450$ mRNA, protein, and function in adulthood, while exposure to phenytoin does not; phenobarbital upregulates the transcription of P450s through its indirect action on the nuclear CAR (Wei et al., 2000). Previous work has shown that direct activation using 1,4-bis[2-(3,5-dichloropyridoyloxy)] benzene, a murine-specific CAR ligand, at the neonatal age also produces permanent alterations to $\mathrm{P} 450$ expression (Li et al., 2016a) and function in adulthood, which alters the efficacy of zoxazolamine administered later in life (Chen et al., 2012). Phenobarbital exposure at the neonatal age also caused a decrease in efficacy of omeprazole administered to adult mice, suggesting its role in a possible nonconventional DDI (Tien et al., 2017). Due to phenytoin's ability to cause CAR activation, we presumed that neonatal exposure would also cause a similar permanent alteration to

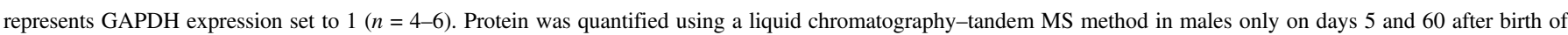

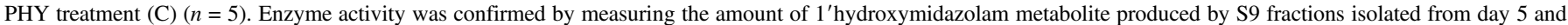

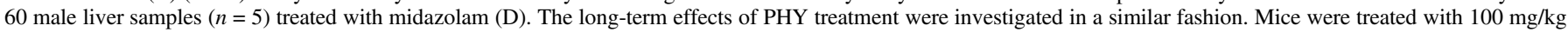

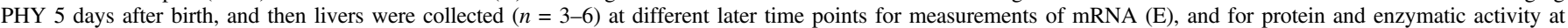
60 days of age $(\mathrm{F}$ and $\mathrm{G})$. The data are presented as mean \pm S.E. $* P<0.05 ; * * P<0.01 ; * * * P<0.001$. 


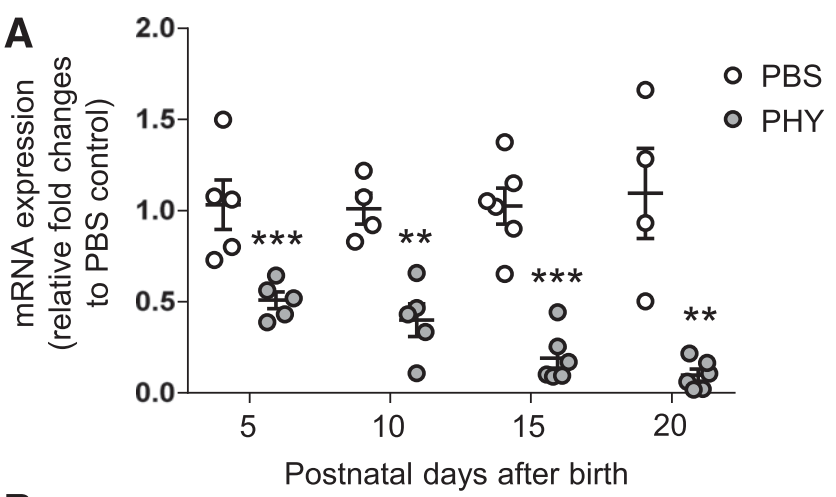

B
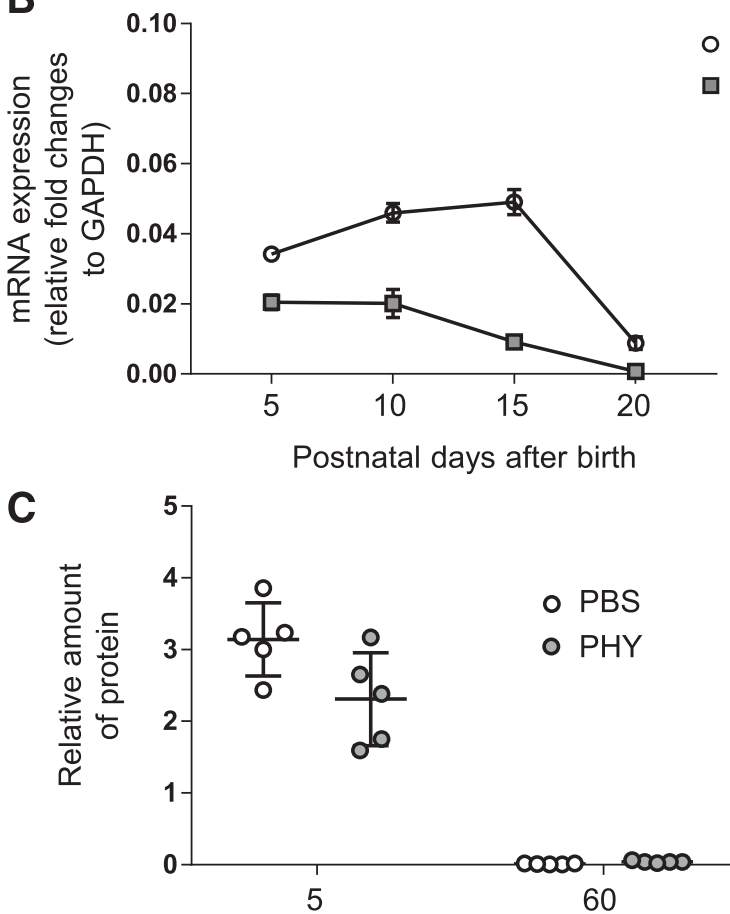

Postnatal days after birth

Fig. 4. Effects of phenytoin (PHY) treatment on the expression of CYP3A16 during postnatal maturation. Male and female mice were treated with either vehicle control (PBS) or $100 \mathrm{mg} / \mathrm{kg}$ PHY at different ages following birth. Twenty-four hours after treatment, livers were collected for quantification of mRNA by RT-PCR $(n=4-6)$. Changes in gene expression were evaluated at the mRNA level using RT-PCR, and then fold changes were calculated using the $2^{-\Delta \Delta \mathrm{Ct}}$ method. Data points represent fold changes in gene expression of individual mice treated with PBS or PHY compared with the average $\Delta \mathrm{Ct}$ of mice that received PBS control (A). Ct values from RT-PCR experiments were also compared with the GAPDH Ct value in each individual mouse and the differences are expressed as $2^{-[\mathrm{Ct}(\mathrm{P} 450)-\mathrm{Ct}(\mathrm{GAPDH})]}(\mathrm{B})$. The dotted line represents GAPDH expression set to $1(n=4-6)$. Protein was quantified using liquid chromatography-tandem MS 24 hours following PHY treatment in male neonates (day 5) and male adults (day 60) (C). The data are presented as mean \pm S.E. $* P<0.05 ; * * P<0.01 ; * * * P<0.001$

P450 expression; however, this was not the case. Unlike 1,4-bis[2-(3,5dichloropyridoyloxy)], both phenobarbital and phenytoin produce CAR activation indirectly. While they both are AEDs, these chemicals have different mechanisms of action for treating seizures. It is plausible that phenobarbital and phenytoin produce indirect CAR activation via separate mechanisms or pathways, and a pathway further upstream of CAR activation is what becomes permanently affected following neonatal phenobarbital treatment that is not impacted by phenytoin treatment.

Phenytoin and phenobarbital are both considered first-line therapy for treating seizures in neonates with phenobarbital appearing to be slightly more efficacious (Painter et al., 1999; Booth and Evans, 2004; Pathak et al., 2013). Both drugs have indications for acute treatment of infant seizures as well as chronic administration for control of epileptic disorders in infants and children. Phenytoin therapy, as with most other AEDs, is initiated with a larger loading dose (18-20 mg/kg for pediatric use), followed by subsequent lower maintenance doses for recurrent seizure control. Appropriate doses are calculated based on the patient's body weight; however, it is unclear whether other factors are taken into account (Hawcutt et al., 2011). In the current study, we administered mice a single dose of $100 \mathrm{mg} / \mathrm{kg}$ phenytoin, which is equivalent to a human dose of $8 \mathrm{mg} / \mathrm{kg}$ according to the Food and Drug Administration's Guidance for Industry to extrapolate human dose concentrations from animal data. This is likely more representative of a maintenance dose of phenytoin; however, this was the maximal dose we could achieve while avoiding excessive toxicity. Perhaps a higher dosing concentration, or multiple-day phenytoin treatment, would have produced the permanent overexpression of P450s that was observed with phenobarbital treatment.

Phenytoin has a narrow therapeutic index with a large propensity to produce ADRs due to patient interindividual variability. Adverse side effects of phenytoin are common and often include rashes, headache, behavioral changes, Steven-Johnson syndrome, cardiovascular collapse, and arrhythmias, especially with rapid intravenous administration, in both children and adults (Bansal et al., 2013; Polat et al., 2015). Many pediatric patients with severe epilepsy are often treated with polytherapy, and interactions between phenytoin and other AEDs and the resulting adverse effects have been documented; for example, concurrent treatment with phenytoin and valproic acid produced phenytoin toxicity in an adolescent epileptic patient despite adhering to pediatric dosing guidelines for phenytoin (Carvalho et al., 2014). A better understanding of the mechanism behind phenytoin-mediated P450 induction via CAR, especially through postnatal development, could help alleviate the high risk of ADRs that commonly accompany phenytoin treatment. Despite the high risk of potentially dangerous side effects, phenytoin might be a better therapeutic option for seizure control in infants since it may not produce the permanent effects on $\mathrm{P} 450$ expression and liver function caused by phenobarbital. These data warrant further studies in humans.

\section{Authorship Contributions}

Participated in research design: Piekos, Zhong, Ma, Zhu.

Conducted experiments: Piekos, Chen, Wang, Shi, Yaqoob.

Performed data analysis: Piekos, Wang, Shi, Ma, Zhu, Zhong.

Wrote or contributed to the writing of the manuscript: Piekos, Zhong, Ma, Zhu.

\section{References}

Abduljalil K, Jamei M, Rostami-Hodjegan A, and Johnson TN (2014) Changes in individual drugindependent system parameters during virtual paediatric pharmacokinetic trials: introducing time-varying physiology into a paediatric PBPK model. AAPS J 16:568-576.

Agrawal AK and Shapiro BH (1996) Imprinted overinduction of hepatic CYP2B1 and 2B2 in adult rats neonatally exposed to phenobarbital. J Pharmacol Exp Ther 279:991-999.

Agrawal AK and Shapiro BH (2005) Neonatal phenobarbital imprints overexpression of cytochromes P450 with associated increase in tumorigenesis and reduced life span. FASEB J 19 470-472.

Bansal D, Azad C, Kaur M, Rudroju N, Vepa P, and Guglani V (2013) Adverse effects of antiepileptic drugs in North Indian pediatric outpatients. Clin Neuropharmacol 36:107-113.

Benjamini Y, Krieger AM, and Yekutieli D (2006) Adaptive linear step-up procedures that control the false discovery rate. Biometrika 93:491-507.

Björkman S (2006) Prediction of cytochrome P450-mediated hepatic drug clearance in neonates, infants and children: how accurate are available scaling methods? Clin Pharmacokinet 45:1-11. Booth D and Evans DJ (2004) Anticonvulsants for neonates with seizures. Cochrane Database Syst Rev 4:CD004218.

Carvalho IV, Carnevale RC, Visacri MB, Mazzola PG, de Fátima Lopes Ambrósio R, dos Reis MC, de Queiroz RA, and Moriel P (2014) Drug interaction between phenytoin and valproic acid in a child with refractory epilepsy: a case report. J Pharm Pract 27:214-216.

Chen WD, Fu X, Dong B, Wang YD, Shiah S, Moore DD, and Huang W (2012) Neonata activation of the nuclear receptor CAR results in epigenetic memory and permanent change of drug metabolism in mouse liver. Hepatology 56:1499-1509. 
Collins BC, Hunter CL, Liu Y, Schilling B, Rosenberger G, Bader SL, Chan DW, Gibson BW, Gingras AC, Held JM, et al. (2017) Multi-laboratory assessment of reproducibility, qualitative and quantitative performance of SWATH-mass spectrometry. Nat Commun 8:291.

Dai D, Feinstein JA, Morrison W, Zuppa AF, and Feudtner C (2016) Epidemiology of polypharmacy and potential drug-drug interactions among pediatric patients in ICUs of U.S. children's hospitals. Pediatr Crit Care Med 17:e218-e228.

de Wildt SN, Kearns GL, Leeder JS, and van den Anker JN (1999) Cytochrome P450 3A: ontogeny and drug disposition. Clin Pharmacokinet 37:485-505.

Dutta S and Sengupta P (2016) Men and mice: relating their ages. Life Sci 152:244-248.

Fabiano V, Mameli C, and Zuccotti GV (2012) Adverse drug reactions in newborns, infants and toddlers: pediatric pharmacovigilance between present and future. Expert Opin Drug Saf 11: $95-105$

Glatter T, Ludwig C, Ahrné E, Aebersold R, Heck AJ, and Schmidt A (2012) Large-scale quantitative assessment of different in-solution protein digestion protocols reveals superior cleavage efficiency of tandem Lys-C/trypsin proteolysis over trypsin digestion. J Proteome Res 11: $5145-5156$.

Gunewardena SS, Yoo B, Peng L, Lu H, Zhong X, Klaassen CD, and Cui JY (2015) Deciphering the developmental dynamics of the mouse liver transcriptome. PLoS One 10:e141220.

Gustafson DL, Long ME, Bradshaw EL, Merz AL, and Kerzic PJ (2005) P450 induction alters paclitaxel pharmacokinetics and tissue distribution with multiple dosing. Cancer Chemother Pharmacol 56:248-254.

Hart SN, Cui Y, Klaassen CD, and Zhong XB (2009) Three patterns of cytochrome P450 gene expression during liver maturation in mice. Drug Metab Dispos 37:116-121.

Hawcutt DB, Sampath S, Timmis A, Newland V, Newland P, and Appleton R (2011) Serum phenytoin concentrations in paediatric patients following intravenous loading. Arch Dis Child 96:883-884.

Hines RN (2008) The ontogeny of drug metabolism enzymes and implications for adverse drug events. Pharmacol Ther 118:250-267.

Hines RN (2013) Developmental expression of drug metabolizing enzymes: impact on disposition in neonates and young children. Int J Pharm 452:3-7.

Jackson JP, Ferguson SS, Negishi M, and Goldstein JA (2006) Phenytoin induction of the Cyp2c37 gene is mediated by the constitutive androstane receptor. Drug Metab Dispos 34:2003-2010.

Lacroix D, Sonnier M, Moncion A, Cheron G, and Cresteil T (1997) Expression of CYP3A in the human liver-evidence that the shift between CYP3A7 and CYP3A4 occurs immediately after birth. Eur J Biochem 247:625-634.

Lam JL, Jiang Y, Zhang T, Zhang EY, and Smith BJ (2010) Expression and functional analysis of hepatic cytochromes P450, nuclear receptors, and membrane transporters in 10- and 25-week-old db/db mice. Drug Metab Dispos 38:2252-2258.

Li CY, Cheng SL, Bammler TK, and Cui JY (2016a) Editor's highlight: neonatal activation of the xenobiotic-sensors PXR and CAR results in acute and persistent down-regulation of PPAR $\alpha$ signaling in mouse liver. Toxicol Sci 153:282-302.

Li CY, Renaud HJ, Klaassen CD, and Cui JY (2016b) Age-specific regulation of drug-processing genes in mouse liver by ligands of xenobiotic-sensing transcription factors. Drug Metab Dispos 44:1038-1049.

Lin JH (2006) CYP induction-mediated drug interactions: in vitro assessment and clinical implications. Pharm Res 23:1089-1116.

Livak KJ and Schmittgen TD (2001) Analysis of relative gene expression data using real-time quantitative PCR and the $2^{-\Delta \Delta C T}$ method. Methods 25:402-408.

Markowitz GJ, Kadam SD, Boothe DM, Irving ND, and Comi AM (2010) The pharmacokinetics of commonly used antiepileptic drugs in immature CD1 mice. Neuroreport 21:452-456.

Martignoni M, Groothuis GM, and de Kanter R (2006) Species differences between mouse, rat, dog, monkey and human CYP-mediated drug metabolism, inhibition and induction. Expert Opin Drug Metab Toxicol 2:875-894.
Painter MJ, Scher MS, Stein AD, Armatti S, Wang Z, Gardiner JC, Paneth N, Minnigh B, and Alvin J (1999) Phenobarbital compared with phenytoin for the treatment of neonatal seizures. $N$ Engl J Med 341:485-489.

Palleria C, Di Paolo A, Giofrè C, Caglioti C, Leuzzi G, Siniscalchi A, De Sarro G, and Gallelli L (2013) Pharmacokinetic drug-drug interaction and their implication in clinical management. $J$ Res Med Sci 18:601-610.

Pathak G, Upadhyay A, Pathak U, Chawla D, and Goel SP (2013) Phenobarbitone versus phenytoin for treatment of neonatal seizures: an open-label randomized controlled trial. Indian Pediatr 50:753-757.

Pearce RE, Gotschall RR, Kearns GL, and Leeder JS (2001) Cytochrome P450 involvement in the biotransformation of cisapride and racemic norcisapride in vitro: differential activity of individual human CYP3A isoforms. Drug Metab Dispos 29:1548-1554.

Peng L, Yoo B, Gunewardena SS, Lu H, Klaassen CD, and Zhong XB (2012) RNA sequencing reveals dynamic changes of mRNA abundance of cytochromes P450 and their alternative transcripts during mouse liver development. Drug Metab Dispos 40:1198-1209.

Piekos S, Pope C, Ferrara A, and Zhong XB (2017) Impact of drug treatment at neonatal ages on variability of drug metabolism and drug-drug interactions in adult life. Curr Pharmacol Rep 3: $1-9$.

Polat I, Karaoglu P, Ayanoglu M, Yis U, and Hiz S (2015) Life-threatening and rare adverse effects of phenytoin. Pediatr Emerg Care 31:e3.

Suzuki Y, Mimaki T, Cox S, Koepke J, Hayes J, and Walson PD (1994) Phenytoin age-doseconcentration relationship in children. Ther Drug Monit 16:145-150.

Tien YC, Liu K, Pope C, Wang P, Ma X, and Zhong XB (2015) Dose of phenobarbital and age of treatment at early life are two key factors for the persistent induction of cytochrome P450 enzymes in adult mouse liver. Drug Metab Dispos 43:1938-1945.

Tien YC, Piekos SC, Pope C, and Zhong XB (2017) Phenobarbital treatment at a neonatal age results in decreased efficacy of omeprazole in adult mice. Drug Metab Dispos 45:330-335.

Treluyer JM, Gueret G, Cheron G, Sonnier M, and Cresteil T (1997) Developmental expression of CYP2C and CYP2C-dependent activities in the human liver: in-vivo/in-vitro correlation and inducibility. Pharmacogenetics 7:441-452.

Turpeinen M, Ghiciuc C, Opritoui M, Tursas L, Pelkonen O, and Pasanen M (2007) Predictive value of animal models for human cytochrome P450 (CYP)-mediated metabolism: a comparative study in vitro. Xenobiotica 37:1367-1377.

Vyhlidal CA, Gaedigk R, and Leeder JS (2006) Nuclear receptor expression in fetal and pediatric liver: correlation with CYP3A expression. Drug Metab Dispos 34:131-137.

Wang H, Faucette S, Moore R, Sueyoshi T, Negishi M, and LeCluyse E (2004) Human constitutive androstane receptor mediates induction of CYP2B6 gene expression by phenytoin. J Biol Chem 279:29295-29301.

Wei P, Zhang J, Egan-Hafley M, Liang S, and Moore DD (2000) The nuclear receptor CAR mediates specific xenobiotic induction of drug metabolism. Nature 407:920-923.

Zanger UM and Schwab M (2013) Cytochrome P450 enzymes in drug metabolism: regulation of gene expression, enzyme activities, and impact of genetic variation. Pharmacol Ther 138 $103-141$.

Zeller B and Giebe J (2015) Pharmacologic management of neonatal seizures. Neonatal Netw 34 239-244.

Address correspondence to: Dr. Xiao-bo Zhong, Department of Pharmaceutical Sciences, School of Pharmacy, University of Connecticut, 69 N Eagleville Road, Storrs, CT 06269. E-mail: xiaobo.zhong@uconn.edu 